\title{
O CONTROLE DE CIRRÍPEDES (CRUSTACEA: CIRRIPEDIA) POR MECANISMOS QUÍMICOS - UM ESTUDO BIBLIOMÉTRICO
}

\author{
Campos, J.M.P. ${ }^{1,2, *}$; Marinho, M.S. ${ }^{1,2}$; Silva, A.K.P. ${ }^{1,3}$ \& Fernandes, M.L.B. ${ }^{1,4}$ \\ ${ }^{1}$ Institulto Avançado de Tecnologia e Inovação (IATI). \\ ${ }^{2}$ Universidade Federal de Pernambuco (UFPE), Campus Recife, Laboratório de Bentos. \\ ${ }^{3}$ Universidade de Pernambuco (UPE), Campus Benfica, Laboratório de Estudos Ambientais. \\ ${ }^{4}$ Universidade de Pernambuco (UPE), Campus Mata Norte, Laboratório de Estudos Ambientais. \\ *Autor correspondente: juli_mcampos@hotmail.com
}

\begin{abstract}
O controle do biofouling é umas das principais linhas de pesquisa sobre organismos marinhos invasores e de incrustação, pois o seu desenvolvimento no casco de embarcações e de outras estruturas artificiais causam danos econômicos e de eficiência. Estimava-se que as incrustações desses organismos custam à economia marítima mais de US\$ 6,5 bilhões por ano. Para solucionar esse problema, tintas e outros compostos foram desenvolvidos e são amplamente utilizados. Alguns organismos marinhos evitam a incrustação de suas superfícies externas através do uso de substâncias naturais de defesa química com propriedades anti-incrustantes sem causar danos ambientais. Portanto, os produtos à base de anti-incrustantes naturais, possuem atividades de inibição potentes, mas sem propriedades biocidas, sendo considerados candidatos ambientalmente amigáveis. Várias pesquisas vêm sendo desenvolvidas na busca de soluções a base de produtos químicos, ecologicamente corretas. Através da utilização do estudo bibliométrico foram encontrados onze trabalhos publicados nos últimos dois anos, a maior parte desses estudos foram desenvolvidos em países asiáticos, principalmente na Central Research Institute of Electric Power Industry. Dentre as substâncias que obtiveram um bom desempenho nos estudos, destaca-se a dolastatina 16, um depsipeptídeo, que poderá proporcionar o controle químico ao assentamento de Cirripedia, principal componente do biofouling que compromete estruturas marinhas submersas.
\end{abstract}

Palavras-chave: biofouling, anti-incrustante, organismos marinhos. 